\title{
Low-grade extraskeletal osteosarcoma of the chest wall: case report and review of literature
}

\author{
Renaud Sabatier ${ }^{1}$, Corinne Bouvier ${ }^{2}$, Gonzague de Pinieux ${ }^{3}$, Anthony Sarran ${ }^{4}$, Isabelle Brenot-Rossi ${ }^{5}$, \\ Florence Pedeutour ${ }^{6}$, Bruno Chetaille ${ }^{7}$, Patrice Viens ${ }^{1,9}$, Pierre-Jean Weiller ${ }^{8,9}$, François Bertucci ${ }^{1,9^{*}}$
}

\begin{abstract}
Background: Low-grade extraskeletal osteosarcomas (ESOS) are extremely rare.

Case presentation: We present the first case of low-grade ESOS of the chest wall, which occurred in a 30-year-old man. Because of initial misdiagnosis and patient's refusal of surgery, the diagnosis was done after a 4-year history of a slowly growing mass in soft tissues, leading to a huge (30-cm diameter) calcified mass locally extended over the left chest wall. Final diagnosis was helped by molecular analysis of MDM2 and CDK4 oncogenes. Unfortunately, at this time, no surgical treatment was possible due to loco-regional extension, and despite chemotherapy, the patient died one year after diagnosis, five years after the first symptoms.

Conclusion: We describe the clinical, radiological and bio-pathological features of this unique case, and review the literature concerning low-grade ESOS. Our case highlights the diagnostic difficulties for such very rare tumours and the interest of molecular analysis in ambiguous cases.
\end{abstract}

\section{Background}

Osteosarcoma (OS) typically develops in the intramedullary cavity of long bones of adolescents and young adults and is a high-grade tumour [1,2]. Extraskeletal osteosarcoma (ESOS) is a very rare form of OS $(\sim 5 \%)$ located in the soft tissues without connection to the skeleton. Its usual aspect is that of a large and deep highgrade bone-forming sarcoma, developed in the limbs of patients older than 40 years [2,3], with a very aggressive behaviour [4].

Low-grade ESOS, whose histology is similar to welldifferentiated intraosseous and parosteal OS, is extremely rare. To date only six cases have been reported in the literature. Here, we describe a new case of lowgrade ESOS, which developed in the chest wall. Initial diagnosis, based on radiological and histological aspects, was erroneously myositis ossificans. Correct final diagnosis, suspected by the clinical evolution, was confirmed by molecular analysis, but was too late, and the patient died from extensive loco-regional progression. We hope that this case report underlines the diagnostic difficulties

\footnotetext{
* Correspondence: bertuccif@marseille.fnclcc.fr

'Department of Medical Oncology, Institut Paoli-Calmettes, 13009 Marseille, France

Full list of author information is available at the end of the article
}

of this tumour, and the interest of molecular analysis in ambiguous cases.

\section{Case presentation}

The patient was a 30-year-old man, Caucasian type, without any specific medical personal or familial history. $\mathrm{He}$ was referred to our institution in November 2006 for diagnosis and treatment of a huge tumour of the left chest wall, detected for the first time 4 years earlier. Indeed, in May 2002, he presented a 3-cm painless, mobile, intramuscular mass on the left shoulder near scapula, three months after a benign trauma on this region. Magnetic resonance imaging (MRI) showed elements in favour of a myositis ossificans circumscripta. Percutaneous biopsy showed areas of osteogenesis with mature bone trabeculae in muscle. The intertrabecular space revealed benign-appearing fibroblastic proliferation. The retained diagnosis was myositis ossificans. The benignity of this disease with usual spontaneous stabilisation or regression [5], and the lack of functional impact of the lesion led the physicians to decide observation.

However, the patient was lost to follow-up, and the mass continued to grow slowly during two years. A second percutaneous biopsy was performed in May 2004. Histological analysis showed an intramuscular tumour 

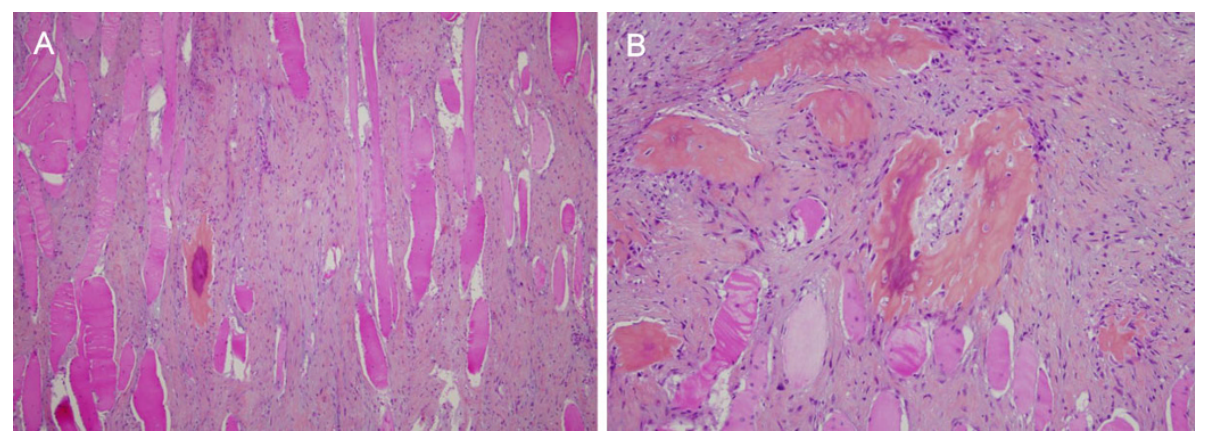

Figure 1 Microscopic features. (A) Proliferation of fusiform cells between muscle fibres (HES $\times 10$ ). (B) Foci of osteogenesis with bland fusiform cells and no mitosis (HES $\times 20$ ).

made of bland fusiform cells with few mitoses and mature bone trabeculae (Figure 1). The morphological features were quite similar to that of the first biopsy, but with some worrisome features such as the absence of classical "zonal phenomenon", and more florid fusiform proliferation and bone forming. Because of the long clinical history and the pathological aspect, the diagnoses of "atypical" myositis ossificans or heterotopic ossification were evoked and a surgical removal was proposed. The patient refused, and consulted another physician who prescribed diphosphonate treatment during a few months.

The patient was then lost to follow-up during 17 months until November 2006, when he was referred to our institution because the mass had kept growing, leading to a shoulder immobilisation. The ECOG status was 1, and the patient presented a frozen left shoulder associated with ipsilateral radial and cubital paralysis and cervical pain. Physical examination found a voluminous, plane, hard and immobile mass extended from the basicervical region to the scapulo-humeral joint and from the left side of the chest wall to the axillary region. Biologically, there was not any abnormality except an elevation of serum alkaline phosphatases. Radiological images were impressive. CT scan showed a huge calcified heterogeneous mass, with kystic and solid elements (Figure 2A). The mass had a 25-cm transversal diameter, an 18-cm antero-posterior diameter and a $30-\mathrm{cm}$ cranio-caudal diameter. It included the left scapula, the periscapular muscles and the chest wall, with intercostal invasion to the pleura and muscular extension to the left arm (triceps). Tc99 bone scan showed a large hyperfixation of the whole left side of the chest (Figure 2B). PET-scan with 18-FDG showed the mass localised in the chest left side, crossing the median line at the first sternocostal joint. Hyperfixation was heterogeneous and moderate with a few highly metabolic zones. A subcutaneous lesion was also observed in the right pectoral muscle (SUV $\max =7 \mathrm{~g} / \mathrm{ml}$ ), as well as pleural abnormalities.
The diagnosis of low-grade ESOS was strongly suspected. For confirmation, the pathological samples removed in May 2004 were collected for re-examination, and notably for molecular analysis of MDM2 and CDK4 oncogenes, whose amplification had been reported in low-grade intraosseous and parosteal osteosarcomas [6-9]. As shown in Figure 3A-B, CDK4 displayed a strong nuclear staining of fusiform cells by immunohistochemistry (IHC), whereas MDM2 had a more focal positivity. Fluorescence in situ hybridization (FISH) analysis showed high amplification for both $M D M 2$ and CDK4 (Figure 3C), confirming the diagnosis of low-grade ESOS.

Unfortunately at this time, more than 4 years after the first symptoms, curative surgical resection was not possible because of to the loco-regional extension. We delivered chemotherapy with an API/AI sequential regimen, which combined adriamycin (A), cisplatinum (P) and ifosfamide (I). The disease was stable after 2 API/AI cycles. After 4 additional API cycles, the disease progressed with extension of cutaneous nodules and tumour mass associated to the apparition of left pleuritis. The ECOG status was 3, and the patient complained of thoracic pain and dyspnoea. Palliative radiation therapy was not possible technically due to the tumour volume. A thoracoscopic talcage was done, followed by trabectedin-based chemotherapy. Three weeks after the first cycle, the patient deteriorated rapidly and died of respiratory failure secondary to loco-regional extension, 5 years after the initial symptoms.

\section{Discussion}

Low-grade ESOS are extremely rare with only 6 cases reported to date in the English literature since 1953 [10-14]. To our knowledge, the present case is the seventh case reported, and the first one developed in the chest wall.

These cases are summarised in Table 1 . The sex ratio is $4 \mathrm{~F} / 3 \mathrm{M}$, and the median age is 40 years. These tumours likely arise from the sarcomatous transformation of 

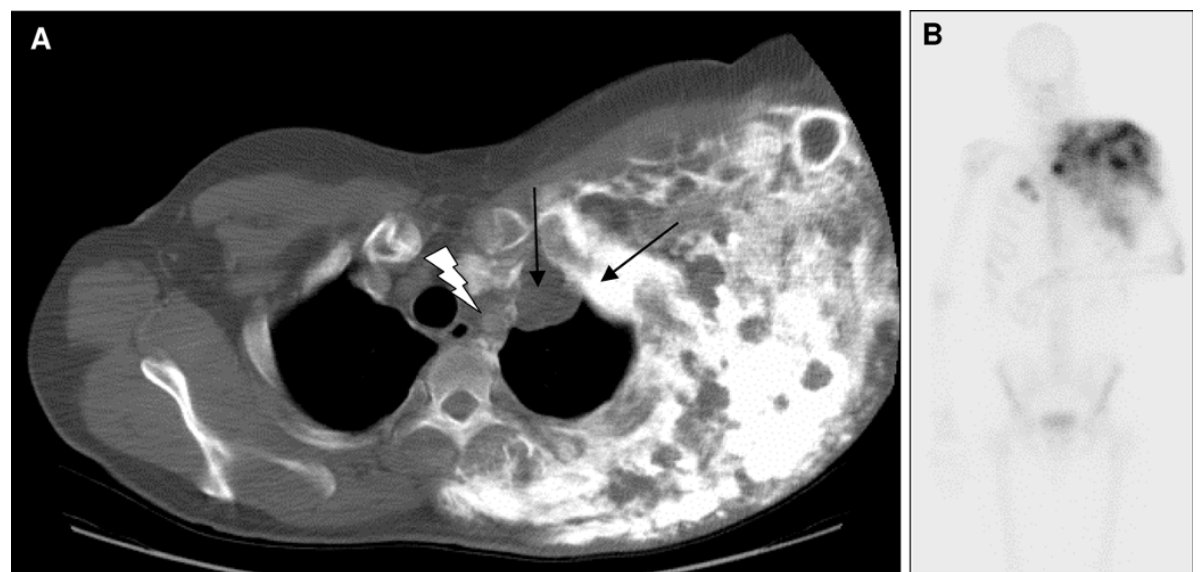

Figure 2 Radiological features $\mathbf{4 . 5}$ years after the first symptoms. (A) CT scan: thoracic transversal view showing a voluminous heterogeneous highly calcified mass. It included the whole left chest wall and the left scapula, with intercostal invasion to the apical pleura (black arrows) and the antero-superior mediastinum (bolt) with trachea deflection to the right. (B) Bone scan with Technecium 99: see the heterogeneous extended hyperfixation of the whole left side of the chest. There was a muscular extension to the triceps leading to a frozen scapulo-humeral joint.

multipotent mesenchymal cells contained in soft tissues. Evolution is slow, and the diagnosis is delayed with a median interval after the discovery of the mass of 4 years (range, 2 to 10 years). This delay explains the large size of tumours at diagnosis (median $14 \mathrm{~cm}$, ranging from 5 to $30 \mathrm{~cm}$ ). However, high-grade histological features (dedifferentiation and high mitotic activity) may appear after a long period in analogy to what happens in low-grade parosteal OS, thus leading to accelerated evolution, like in our case with rapid loco-regional extension, or in two cases with metastatic diffusion [10,14]. Early diagnosis of this tumour is crucial to allow an adequate surgical resection, which represents the sole curative treatment, as confirmed by the prolonged complete remissions observed in the 4 out of 5 patients initially treated with complete surgery.
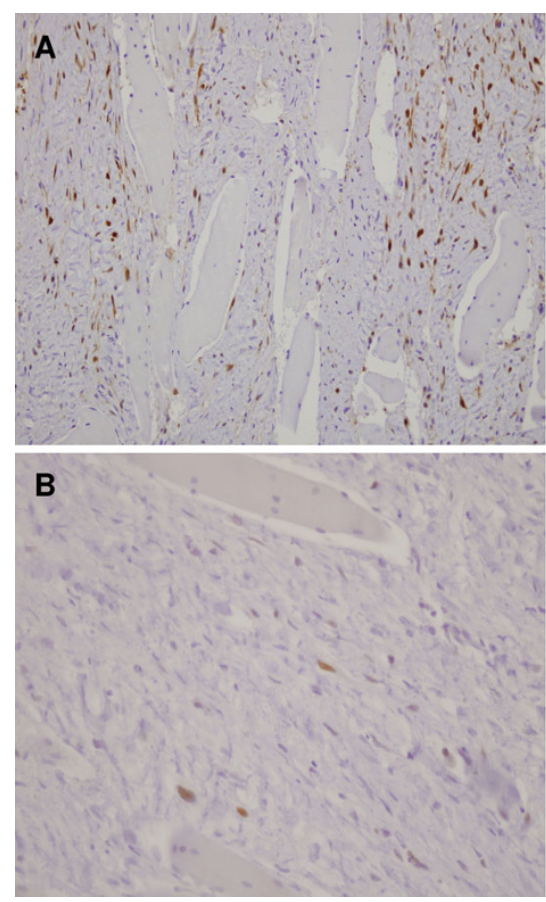

Figure 3 CDK4 and MDM2 analysis. (A) Immunohistochemistry with anti-CDK4 antibody showing strong and quite diffuse nuclear staining of fusiform cells $(\times 20)$. (B) Immunohistochemistry with anti-MDM2 antibody showing a more focal nuclear positivity. (C) Fluorescence in situ hybridization of one neoplasic cell: high nuclear amplification of CDK4 (red signals) and MDM2 (green signals), with more than 20 copies ( $\times$ 40). 
Table 1 Seven cases of low-grade ESOS reported in literature

\begin{tabular}{|c|c|c|c|c|c|c|}
\hline Ref. & $\begin{array}{l}\text { Sex/ } \\
\text { Age }\end{array}$ & $\begin{array}{c}\text { Initial } \\
\text { diagnosis }\end{array}$ & Tumour location & $\begin{array}{l}\text { Largest } \\
\text { diameter }\end{array}$ & Treatment & Clinical outcome \\
\hline [10] & $M / 44$ & $\begin{array}{l}\text { Myositis } \\
\text { ossificans }\end{array}$ & Right thigh & $5 \mathrm{~cm}$ & S & Lung metastases, 4 years, death \\
\hline [11] & $\mathrm{F} / 57$ & Low-grade ESOS & $\begin{array}{l}\text { Right popliteal } \\
\text { fossa }\end{array}$ & $24 \mathrm{~cm}$ & S & $\begin{array}{l}\text { Disease-free, } \\
5 \text { years }\end{array}$ \\
\hline [12] & $\mathrm{F} / 74$ & Parosteal OS & Left axilla & $14 \mathrm{~cm}$ & S & $\begin{array}{l}\text { Disease-free, } \\
2 \text { years }\end{array}$ \\
\hline [13] & $F / 35$ & $\begin{array}{l}\text { Myositis } \\
\text { ossificans }\end{array}$ & Left leg & $11 \mathrm{~cm}$ & S & $\begin{array}{l}\text { Disease-free, } \\
4 \text { years }\end{array}$ \\
\hline [14] & $\mathrm{F} / 40$ & Parosteal OS & Back, para-spinal & $9 \mathrm{~cm}$ & S & $\begin{array}{l}\text { Lost to follow-up, } \\
2 \text { months }\end{array}$ \\
\hline [14] & $M / 32$ & Low-grade ESOS & $\begin{array}{l}\text { Right thigh } \\
\text { and others }\end{array}$ & $16 \mathrm{~cm}$ & $\mathrm{~S}+\mathrm{CT}$ & Lung and retroperitoneum metastases, 4 years, death \\
\hline $\begin{array}{l}\text { Our } \\
\text { case }\end{array}$ & $M / 30$ & $\begin{array}{l}\text { Myositis } \\
\text { ossificans }\end{array}$ & Chest & $30 \mathrm{~cm}$ & CT & $\begin{array}{c}\text { Loco-regional extension, } \\
\text { death } 5 \text { years after first symptoms and } 1 \text { year after } \\
\text { diagnosis }\end{array}$ \\
\hline
\end{tabular}

M, male; F, female; ESOS, extraskeletal osteosarcoma; OS, osteosarcoma; S, surgery; CT, chemotherapy.

However, differential diagnosis may be problematic at early stages with other ossified lesions of soft tissues: benign lesions such as myositis ossificans circumscripta (MOC), ossifying lipoma, soft tissue osteoma or chondroma, and ossifying fibromyxoid tumour, as well as malignant lesions such as classical high-grade ESOS, parosteal OS, mesenchymal chondrosarcoma, and synovial sarcoma. MOC is a benign heterotopic ossification of soft tissues characteristically associated with direct trauma [15]. It is one of the most important differential diagnoses, which was initially evoked - based on radiological and/or pathological aspects - in at least 3 out of the 7 reported cases of low-grade ESOS. Furthermore, a number of cases of ESOS presumably arising from MOC have been reported [16-19]. In MOC, both mature and immature bone is seen, as well as a prominent spindle cell and chondroid component, with a specific architecture described as the "zonal phenomenon". This phenomenon refers to the presence of a clearly benign, reactive rim of mature bone at the periphery, which encompasses a central area of fusiform cells and immature bone interlaced with osteoid and chondroid. In our patient, several initial aspects led physicians to erroneously propose this diagnosis: i) the initial traumatism a few weeks before the discovery of the tumour, ii) the first MRI observation which showed an extraosseous mass with a mature calcification peripherally predominant, iii) and the pathological aspects of mature lamellar bone synthesis by non atypical cells without abnormal mitoses. However, the radiological modifications observed later with the development of a centrifuge ossification corresponding to microscopic features to a reverse pattern of ossification ("reverse zonal phenomenon"), and of course, the progressive tumour growth and extension were that of a malignant tumour. Due to the initial misdiagnosis followed by the absence of follow-up, and the patient's refusal of surgery, the correct diagnosis was done too late and evolution was fatal.

Today, molecular analyses may resolve the diagnostic dilemma between low-grade ESOS and benign lesions. Amplification of genes in the 12q13-15 region, such as $S A S, C D K 4$ and $M D M 2$, is relatively frequent in osteosarcoma, notably in low-grade parosteal OS, making them suitable as markers for distinguishing them from benign ossifying [6-9]. In our patient, IHC and FISH analyses for MDM2 and CDK4 were done on 2006 from paraffin-embedded tumour samples biopsied on 2004. They showed the overexpression and amplification of these two oncogenes, thus ruling out the diagnosis of myositis ossificans and confirming that of sarcoma. To our knowledge, it is the first case of low-grade ESOS with documented molecular alterations.

\section{Conclusion}

Our case is the seventh case of low-grade ESOS reported in literature, and the first case located in the chest wall. It highlights the importance and difficulty of early diagnosis of this very rare tumour, which may be confused with numerous benign diseases, notably myositis ossificans. Misdiagnosis may be fatal, as surgery is the only curative approach for these patients. In this context, it is worth noting the importance of molecular analysis (amplification and/or ovexpression of MDM2 and $C D K 4$ ) to help diagnosis in ambiguous cases.

\section{Consent}

Written informed consent was obtained from the patient's relatives for publication of this case report and any accompanying images. 


\section{Author details}

'Department of Medical Oncology, Institut Paoli-Calmettes, 13009 Marseille, France. ${ }^{2}$ Department of Pathology, CHU La Timone, 13005 Marseille, France. ${ }^{3}$ Department of Pathology, Hôpital Trousseau, 37000 Tours, France.

${ }^{4}$ Department of Radiology, Institut Paoli-Calmettes, 13009 Marseille, France. ${ }^{5}$ Department of Nuclear Medicine, Institut Paoli-Calmettes, 13009 Marseille, France. ${ }^{6}$ Laboratory of Solid Tumours Genetics, University of Nice-SophiaAntipolis, CNRS UMR 6543, Nice University Hospital, 06000 Nice, France. ${ }^{7}$ Department of Pathology, Institut Paoli-Calmettes, 13009 Marseille, France. ${ }^{8}$ Department of Internal Medicine, CHU La Timone, 13005 Marseille, France. ${ }^{9}$ University of Mediterranea, Marseille, France.

\section{Authors' contributions}

$\mathrm{RS}$ and FB conceived and designed the study, and wrote the manuscript. FB, PJW, PV, AS and IBR participated in patient's management. CB, GdP, FP, BC made the pathological and molecular explorations. All authors read and approved the final manuscript

\section{Competing interests}

The authors declare that they have no competing interests.

Received: 21 May 2010 Accepted: 24 November 2010

Published: 24 November 2010

\section{References}

1. Huvos AG: Bone tumors. Diagnosis, treatment and prognosis. Philadelphia: WB Saunders; 21991.

2. Bane BL, Evans HL, Ro JY: Extraskeletal osteosarcoma: a clinicopathologic review of 26 cases. Cancer 1990, 66:2762-2770.

3. Chung EB, Enzinger FM: Extraskeletal osteosarcoma. Cancer 1987, 60:1132-1142.

4. Enzinger FM, Weiss SW: Soft tissue sarcomas. St Louis: Mosby-Year Book; 1995.

5. Bernard M, Coumbaras $M$, Zeitoun F, Arrivé L, Tubiana JM, Le Hir P: Radiological spectrum of myositis ossificans circumscripta evolution. $J$ Radiol 2003, 84(1):54-56.

6. Gamberi G, Ragazzini P, Benassi MS, Ferrari C, Sollazzo MR, Molendini L, Merli M, Magagnoli G, Ruggieri P, Balladelli A, Orlando C, Bacchini P, Pazzagli M, Picci P: Analysis of 12q13-15 genes in parosteal osteosarcoma. Clinical Orthopaedics Related Research 2000, , 377: 195-204.

7. Gisselsson D, Pålsson E, Höglund M, Domanski H, Mertens F, Pandis N, Sciot R, Dal Cin P, Bridge JA, Mandahl N: Differentially amplified chromosome 12 sequences in low- and high-grade osteosarcoma. Genes Chromosomes Cancer 2002, 33(2):133-140.

8. Wunder JS, Eppert K, Burrow SR, Gokgoz N, Bell RS, Andrulis IL: Coamplification and overexpression of CDK4, SAS and MDM2 occurs frequently in human parosteal osteosarcomas. Oncogene 1999, 18:783-788.

9. Ragland BD, Bell WC, Lopez RR, Siegal GP: Cytogenetics and molecular biology of osteosarcoma. Laboratory Investigation 2002, 82:365-373.

10. Umiker W, Jaffe HL: Ossifying fibrosarcoma (extraskeletal osteogenic sarcoma) of thigh muscle; report of a case with recurrence and widespread metastases more than four and a half years after excision. Annals of Surgery 1953, 138(5):795-800.

11. Present D, Bertoni F, Laus M, Bacchini P, Bocanera M: Case report 565: Low-grade osteosarcoma of soft tissues (popliteal fossa). Skeletal Radiology 1989, 18(6):471-474.

12. Yi ES, Shmookler BM, Malawer MM, Sweet DE: Well-differentiated extraskeletal osteosarcoma. A soft-tissue homologue of parosteal osteosarcoma. Archives of Pathology and Laboratory Medicine 1991, 115(9):906-909.

13. Okada K, Ito H, Miyakoshi N, Sageshima M, Nishida J, Itoi E: A low-grade extraskeletal osteosarcoma. Skeletal Radiology 2003, 32(3):165-169.

14. Abramovici LC, Hytiroglou P, Klein RM, Karkavelas G, Drevelegas A, Panousi E, Steiner GC: Well-differentiated extraskeletal osteosarcoma: report of 2 cases, 1 with dedifferentiation. Human Pathology 2005, 36(4):439-443

15. Ogilvie-Harris DJ, Fornasier VL: Pseudomalignant myositis ossificans: heterotopic new-bone formation without a history of trauma. Journal of Bone and Joint Surgery American volume 1980, 62:1274-1283.
16. Konishi E, Kusuzaki K, Murata H, Tsuchihashi Y, Beabout JW, Unni KK: Extraskeletal osteosarcoma arising in myositis ossificans. Skeletal Radiology 2001, 30:39-43.

17. Huvos AG, Heilweil M, Bretsky SS: The pathology of malignant fibrous histiocytoma of bone. A study of 130 patients. American Journal of Surgical Pathology 1985, 9:853-871.

18. Shanoff LB, Spira M, Hardy SB: Myositis ossificans: evolution to osteogenic sarcoma. Report of a histologically verified case. American Journal of Surgery 1967, 113:537-541.

19. Järvi OH, Kvist HT, Vainio PV: Extraskeletal retroperitoneal osteosarcoma probably arising from myositis ossificans. Acta Pathologica Microbiology Scandinavia 1968, 74:11-25.

\section{Pre-publication history}

The pre-publication history for this paper can be accessed here: http://www.biomedcentral.com/1471-2407/10/645/prepub

doi:10.1186/1471-2407-10-645

Cite this article as: Sabatier et al:: Low-grade extraskeletal osteosarcoma of the chest wall: case report and review of literature. BMC Cancer 2010 10:645

\section{Submit your next manuscript to BioMed Central and take full advantage of:}

- Convenient online submission

- Thorough peer review

- No space constraints or color figure charges

- Immediate publication on acceptance

- Inclusion in PubMed, CAS, Scopus and Google Scholar

- Research which is freely available for redistribution

Submit your manuscript at www.biomedcentral.com/submit
Ciomed Central 